\title{
Stress levels predict substantial improvement in pain intensity after 10 to 12 years in women with fibromyalgia and chronic widespread pain: a cohort study
}

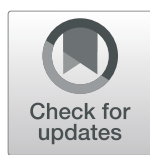

Anna Bergenheim ${ }^{1,2,3^{*}}$ (D) Sofia Juhlin ${ }^{1,2,3}$, Lena Nordeman ${ }^{1,2}$, Monica Joelsson ${ }^{3}$ and Kaisa Mannerkorpi ${ }^{1}$

\begin{abstract}
Background: Previous studies of prognosis for women with Fibromyalgia (FM) or chronic widespread pain (CWP) show contradictory results. However, some women appear to improve in pain and other core symptoms over time. There is limited knowledge about predictors of substantial improvement in pain intensity over a longer period of time. The primary objective of this study was to investigate the natural course of pain intensity and distribution of pain over 10 to 12 years in a cohort of 166 women with FM or CWP. Secondarily we wanted to investigate predictors of substantial improvement $(\geq 50 \%)$ in pain intensity after 10 to 12 years.
\end{abstract}

Methods: The study is a longitudinal prospective cohort study. 166 women with FM or CWP were followed up after 10 to 12 years. 126 women (76\%) participated in the follow-up and completed a battery of questionnaires concerning pain intensity, pain distribution and other physical and mental aspects of health. Differences in symptoms within the cohort over 10 to 12 years and predictors of substantial improvement $(\geq 50 \%)$ in pain intensity were calculated.

Results: Pain had improved at the 10 to 12 year follow-up $(p<0.001)$ with a mean change of $-9.2 \mathrm{~mm}$ (SD $23.3,95 \% \mathrm{Cl}$ : -13.3 ; - 5.0) for pain intensity and -2.0 sites (SD 4.2, 95\% Cl: - 2.7; - 1.2) for pain distribution. Nine percent of the 126 women showed an individual moderate improvement in pain intensity while $16 \%$ showed a substantial improvement at the follow-up as compared to baseline. Lower symptoms of stress and higher pain intensity at baseline predicted higher probability of reporting at least $50 \%$ less pain intensity after 10 to 12 years as compared to baseline.

Conclusions: A majority of women with FM and CWP appear to have a positive course of pain over time, which should be communicated to these patients in health care. Reducing stress levels might contribute to better chances of improvement over time.

Trial registration: Clinicaltrials.gov NCT02872129, registered 06/30/2016.

Keywords: Fibromyalgia, Chronic pain, Follow-up, Longitudinal

\section{Background}

The prevalence of chronic widespread pain (CWP) is about 7 to $13 \%$ of the population in the western world $[1,2]$. CWP has been defined as pain in both body sides, above and below the waist plus axial pain, present for at

\footnotetext{
* Correspondence: anna.c.bergenheim@vgregion.se

${ }^{1}$ Institute of Neuroscience and Physiology, Department of Health and Rehabilitation, Physiotherapy Unit, Sahlgrenska Academy, University of Gothenburg, Gothenburg, Sweden

${ }^{2}$ Research and Development Primary Health Care, Region Västra Götaland, Sweden

Full list of author information is available at the end of the article
}

least 3 months [3]. 1 to $3 \%$ of the general population constitute a subgroup of CWP with more severe symptoms $[2,4]$, fulfilling the tender point criteria for Fibromyalgia (FM) [3]. Besides pain and tenderness, FM and CWP is associated with stiffness, severe fatigue, psychological distress and cognitive difficulties [4-6]. Persons with FM or CWP have also been found to be less physically active and to have lower physical capacity than healthy individuals [7], which increases the risk to develop concomitant disorders.

(C) The Author(s). 2019 Open Access This article is distributed under the terms of the Creative Commons Attribution 4.0 International License (http://creativecommons.org/licenses/by/4.0/), which permits unrestricted use, distribution, and 
The results of previous longitudinal studies are contradictory. In a 3 year follow-up [8] of the course of symptoms in 59 women with FM, significant improvements were found for pain intensity and number of tender points and $36 \%$ of the women achieved at least 30\% improvement in pain intensity. Also, the percentage of patients experiencing widespread pain was reduced from 100 to $63 \%$ [8]. Similarly, in a comprehensive follow-up in a general population in Norway, $47 \%$ of the persons who reported CWP at baseline had recovered from CWP after 11 years [9]. On the contrary, a longitudinal study including over 3000 participants with FM found no clinically relevant improvements in pain, fatigue or self-rated functional status over 10 years [10]. Other longitudinal studies in patients with FM have not found improvement in pain intensity over 5 to 6 years, but in overall health $[11,12]$.

To the best of our knowledge, there are no accepted limits representing moderate and substantial improvement in pain intensity in cohort studies of chronic pain. A $15 \%$ reduction in pain intensity on a numeric rating scale has been suggested to reflect minimal clinical important difference while a $33 \%$ reduction in pain intensity has been suggested to represent a "much better" improvement in cohorts of chronic musculoskeletal pain [13]. Improvements in pain intensity in clinical trials are recommended to be presented as change both on group-level and on individual level as number of persons improving at least 30\% (moderate improvement) and 50\% (substantial improvement) from baseline for numeric rating scales or Visual Analogue Scales (VAS) [14]. The same limits for moderate and substantial improvement have been used in a large cohort study in persons with FM [15], and were also applied in the present cohort study.

There is limited knowledge of why some patients achieve substantial improvement in pain over time while others do not. A Swedish postal survey showed that higher health related quality of life at baseline in persons with chronic pain increased the chances of no longer having chronic pain after 3 years [16]. On the other hand, factors such as being a woman, having lower education, high Body Mass Index (BMI), higher levels of depression and anxiety, worse sleep, being former smoker or having other concomitant disorders have been found to predict an increased risk of still having CWP after 11 years [9].

Most follow-up studies have been conducted after three to 6 years, and the knowledge of the course of symptoms in FM and CWP over a longer period appear to be scarce.

In the present study, we conducted a follow-up of 166 women with FM or CWP, in order to examine how pain and other health related aspects change over 10 to 12 years, and also if psychological and physical aspects of health could predict the long-term change in pain intensity.

\section{Objectives}

The primary objective of this study was to investigate the natural course of pain intensity and distribution of pain over 10 to 12 years in a cohort of 166 women with FM or CWP. Secondarily, we wanted to investigate predictors of substantial improvement in pain intensity after 10 to 12 years.

Also, we were interested in investigating the natural course over 10 to 12 years in overall health, global fatigue, depression and anxiety, symptoms of stress and health related quality of life.

\section{Methods \\ Study design \\ A longitudinal cohort study.}

\section{Patients and methods Participants}

In the year of 2004-2005, 166 women with FM or CWP recruited in primary care in western Sweden participated in a randomized controlled trial (RCT) called the GAU-study, comparing a patient education program in combination with 20 weeks of pool exercise with a control group participating in a patient education program as only treatment [17]. All participants completed a battery of questionnaires regarding symptoms and health and performed tests of physical function at baseline. The impact of a 20 week intervention was considered to be negligible after 10 to 12 years, thus the whole cohort of 166 women were eligible for recruitment in the present follow-up of natural course of symptoms over time.

Inclusion criteria The 166 women with FM or CWP who participated in the baseline examination of the GAU study 2004-2005 [17] were invited to participate in the present study. The inclusion criteria of the GAU study [3] were women with FM or CWP, in the age range 18-60 years. CWP was classified as pain above and below the waist, at the right and left side of the body and axial pain for at least 3 months. FM was classified as having CWP in combination with pain at manual palpation at 11 out of a total of 18 examined tender-point localizations [3]. The exclusion criteria of the GAU-study 2004-2005 were other severe somatic or psychiatric disorders or ongoing exercise therapy supervised by a physical therapist [3].

Exclusion criteria Participants who had deceased, or developed serious physical or psychological disease since they were included in the GAU-study, such as cancer during treatment, stroke with severe physical impairment or schizophrenia. 


\section{Recruitment}

All 166 women received a letter with information about the present study, except four participants who were deceased. The letter was followed up for the 162 participants by telephone for more information about the study and invitation to participate. Those who could not be reached by phone received a second letter with inquiry about new contact information. Eight persons were excluded during the phone call according to exclusion criteria, and 19 declined to participate. Nine could not be reached. A final total of 126 women (76\%) participated in the present follow-up.

\section{Data collection}

\section{Procedure}

The examinations were performed by trained physical therapists who were blinded to previous baseline test results. The examinations took place at rehabilitation centers in the three cities Göteborg, Alingsås and Uddevalla in western Sweden, from April to December 2016. The same measurements that were used at baseline were included in the follow-up examination which lasted about $1.5 \mathrm{~h}$ and included a battery of questionnaires, physical examination of tender points [3] and tests of physical function and a standardized interview with questions about duration of pain, employment status, sick leave and disability pension, education, marital status, concomitant disorders and medications.

\section{Background data}

Employment was divided into four categories referring to percentage of full time work, which is defined as $40 \mathrm{~h}$ per week.

Sick leave and Disability pension were categorised as 0, $25,50,75 \%$ or $100 \%$ sick leave/disability pension.

Marital status referred to whether the patient lived with another adult or not.

Education was divided into three categories referring to years of education since 1st grade: $\leq 9$ years $/ 9-12$ years/> 12 years.

Medications. Use of analgesics/NSAID and psychotropics (meaning antidepressants and sedatives) was registered as positive when use was regular or as needed.

\section{Self-administered questionnaires at baseline and follow-up}

Pain distribution (0-18) The localization and distribution of pain were reported in a self-administered pain drawing with 18 predefined body regions [18].

The Fibromyalgia Impact Questionnaire (FIQ) (0100) The FIQ comprises 10 subscales of disabilities and symptoms, ranging from 0 to 100 [19], and it is validated for a Swedish FM population [20]. A higher total score indicates lower overall health status. The FIQ total score is calculated by the mean of the ten subscales [19]. A total score $<39$ is considered to represent mild impairment, $\geq 39$ to $>59$ moderate impairment and $\geq 59$ severe impairment [21]. The FIQ subscales for Pain intensity (FIQ pain) and global fatigue (FIQ fatigue) were also applied in the present study. The patients estimated their pain intensity/ how tired they had been during the previous week on a VAS, ranging from 0 to $100 \mathrm{~mm}$ [19].

The Hospital Anxiety and Depression Scale (HADS) (0-21) The HADS contains 14 statements, rated from 0 to 3 . The scores build two subscales for anxiety (HADSA) and depression (HADS-D), each ranging from 0 to 21 , and higher scores indicate a higher degree of distress [22]. .A cut-off score of eight is suggested to indicate possible anxiety or depression [23].

Stress and Crisis Inventory (SCI-93) (0-140) The SCI93 comprises 35 clinical manifestations of stress. The participants rated to what extent they are interfered by the different symptoms in their daily life on a scale ranging from 0 "not at all" to 4 "very much". The items include physical and mental sensations. The total score ranges from 0 to 140 and a higher score indicates more stress [24].

Short-form 36 (SF-36) (0-100) The SF-36 is a generic instrument assessing health related quality of life, comprising eight subscales. The subscales build two composite scores, the Physical Component Summary (PCS) and the Mental Component Summary (MCS), ranging from 0 to 100. A higher score indicates better health related quality of life [25].

Leisure Time Physical Activity Instrument (LTPAI) (h) The LTPAI assesses the amount of physical activity during a typical week. The LTPAI total score is the sum of hours for the activities [26].

\section{Tests of physical function at baseline}

Six-minute walk test (6MWT) (m) The patient was instructed to walk as quickly as she could without running and the baseline values of the distance in metres covered in 6 min was used as a measure of walking capacity in the analyses of predictors of improvement in pain intensity in the present study. The test has shown satisfactory testretest reliability in a Swedish FM population [27]. The $6 \mathrm{MWT}$ was used only in the analyses of predictors of improvement of pain intensity in the present study. 


\section{Statistics}

Descriptive statistics are presented as mean, standard deviation (SD) and range (min-max) for continuous variables and as number and percent for categorical variables.

For comparisons over time within the cohort, Wilcoxon's Signed rank test was used for change over time in continuous variables and Sign test for dichotomous and ordinal categorical variables. Bootstrapped (10000 replicates) $95 \%$ confidence intervals were calculated for change over time in continuous variables.

Logistic regression analyses were used to analyze which variables were significant predictors of improvement in pain intensity [28]. Dependent variable was at least $50 \% \mathrm{im}$ provement in pain intensity as reported on FIQ pain after 10 to 2 years $(0=<50 \%$ improvement or no improvement/ $1=\geq 50 \%$ improvement). Independent variables were baseline values for age, education, BMI, FIQ total score, FIQ pain, HADS-A, HADS-D, SF-36 PCS, SF-36 MCS, LTPAI, 6MWT and group of randomization in previous RCT.

Odds ratios (OR) with $95 \%$ confidence intervals and $p$ values are presented.

The independent variables that were associated $(p<0.1)$ with the dependent variable in the univariable logistic regression analyses were included in the multivariable forward stepwise logistic regression analysis. All univariable regression analyses were adjusted for FIQ pain at baseline. Odds ratios (OR) with 95\% confidence intervals, p-values and area under the receiving operating curve (AUC) values [29] are presented. AUC-values ranging from 0.7 to 0.8 indicate acceptable goodness of the model, values from 0.8 to 0.9 indicate excellent goodness and over 0.9 indicate outstanding goodness of the model [29]. For comparisons between patients followed-up and lost to follow-up, the Mann Whitney U-test was used for continuous variables, Fisher's exact test for dichotomous variables and MantelHaenszel chi-square test for ordinal categorical variables.

\section{Results}

\section{Study population}

Baseline descriptive data for the 126 patients in the follow-up as well as for the 40 patients who did not participate in the follow-up are presented in Table 1.

There were no significant differences in baseline values for descriptive data or the primary outcomes pain intensity and distribution of pain, between the participants who participated in the follow-up and the ones who did not, except for the number of tender points (Table 1).

\section{Change from baseline to follow-up in pain intensity and distribution of pain}

There was a significant $(p<0.001)$ improvement in pain intensity (FIQ pain) and distribution of pain at the 10 to 12 year follow-up (Table 2).
In pain intensity (FIQ Pain), 11 (9\%) of the women showed an individual moderate improvement of 30 to $50 \%$ and 20 women (16\%) showed a substantial improvement of $\geq 50 \%$ at the follow-up as compared to baseline. Nine (7\%) had a moderate worsening of pain intensity of 30 to $50 \%$ and $7(6 \%)$ had a substantial worsening of $\geq 50 \%$. The remaining 76 women $(60 \%)$ remained either unchanged, $<30 \%$ improvement or $<30 \%$ worsened. Missing data was found for three women (2\%) in FIQ pain, why the change in pain intensity was calculated for 123 of the 126 women.

\section{Change from baseline to follow-up in other health related aspects}

The 126 women improved on group-level over 10 to 12 years in overall health as assessed with the FIQ total score (Table 2). The distribution of proportions in categories of impairment [21] at baseline and the 10 to 12 year follow-up is presented in Table 3.

The 126 women improved significantly in Global fatigue (FIQ fatigue) $(p=0.001)$, depression (HADS-D) $(p=0.021)$, the physical component of health related quality of life (SF-36-PCS) $(p<0.001)$ and symptoms of stress (SCI-93) $(p=0.005)$ at the 10 to 12 year follow-up as compared to baseline (Table 2). There were no significant change in anxiety (HADS-A), the mental component of health related quality of life (SF-36 MCS) or the level of physical activity (LTPAI) at the 10 to 12 year follow-up (Table 2).

\section{Predictors of $\geq \mathbf{5 0} \%$ improvement in pain intensity}

Significant univariable predictors of at least $50 \% \mathrm{im}$ provement in FIQ pain were baseline values of FIQ total, HADS depression, SCI-93 and SF-36 MCS (Table 4). These four variables together with FIQ pain baseline were included in the multivariable forward stepwise logistic regression analysis. The result showed that SCI93 (OR 0.69, 95\% CI: 0.53-0.89, $p=0.004$ ) and FIQ pain (OR 1.49, 95\% CI: 1.08-2.07, $p=0.016$ ) contributed to the strongest model (AUC: 0.730 ) for predictors of a reduction in pain intensity with at least $50 \%$. Lower symptoms of stress and higher pain intensity at baseline predicted higher probability of reporting $50 \%$ less pain intensity after 10 to 12 years as compared to baseline.

\section{Discussion}

The present study assessed the course of symptoms over 10 to 12 years in a cohort of women with FM and CWP as well as predictors of substantial improvement in pain intensity.

The women were found to improve over time in pain intensity. The mean improvement for pain intensity for the study population was $9 \mathrm{~mm}$ on a $100 \mathrm{~mm}$ VAS which correspond to a $13 \%$ change from baseline on group-level. 
Table 1 Baseline descriptive data for the 126 patients who participated in the follow-up and the 40 patients who were not followed up, and $p$-values for difference between groups

\begin{tabular}{|c|c|c|c|}
\hline & Followed up $(n=126)$ & Not followed up $(n=40)$ & $p$-value \\
\hline & Mean (SD), Min;Max & Mean (SD), Min;Max & \\
\hline Age, years & 45.4 (8.6), 22;60 & $46.3(9.5), 24 ; 59$ & 0.51 \\
\hline Duration of WP, years & $10.4(7.2), 0.3 ; 45$ & $10.6(7.0), 1.0 ; 30$ & 0.80 \\
\hline Tender points, $n$ & $13.8(3.5), 3 ; 18$ & $12.6(3.4), 6 ; 18$ & 0.023 \\
\hline FIQ pain, $(0-100 \mathrm{~mm})$ & $68.3(18.7), 20 ; 100$ & $71.5(18.0), 22 ; 100$ & 0.31 \\
\hline \multirow[t]{2}{*}{ Pain distribution, (0-18) } & $13.0(3.4), 4 ; 18$ & $12.5(3.4), 5 ; 18$ & 0.38 \\
\hline & n (\%) & n (\%) & \\
\hline Education & & & 0.79 \\
\hline$\leq 9$ years & $29(23 \%)$ & $9(23 \%)$ & \\
\hline $10-12$ years & $69(55 \%)$ & $20(50 \%)$ & \\
\hline$<12$ years & $28(22 \%)$ & $10(25 \%)$ & \\
\hline Work status & & & 0.92 \\
\hline $0 \%$ & $73(58 \%)$ & $25(63 \%)$ & \\
\hline $1-49 \%$ & $14(11 \%)$ & $0(0 \%)$ & \\
\hline $50-79 \%$ & $28(22 \%)$ & $9(23 \%)$ & \\
\hline $80-100 \%$ & $11(9 \%)$ & $6(15 \%)$ & \\
\hline Sick-leave & & & 0.98 \\
\hline $0 \%$ & $66(52 \%)$ & $21(52 \%)$ & \\
\hline $25 \%$ & $5(4 \%)$ & $3(8 \%)$ & \\
\hline $50 \%$ & $17(13 \%)$ & $4(10 \%)$ & \\
\hline $75 \%$ & $2(2 \%)$ & $0(0 \%)$ & \\
\hline $100 \%$ & $36(29 \%)$ & $12(30 \%)$ & \\
\hline Disability pension & & & 0.59 \\
\hline $0 \%$ & $74(59 \%)$ & $26(65 \%)$ & \\
\hline $25 \%$ & $4(3 \%)$ & $0(0 \%)$ & \\
\hline $50 \%$ & $17(14 \%)$ & $5(13 \%)$ & \\
\hline $75 \%$ & $3(2 \%)$ & $0(0 \%)$ & \\
\hline $100 \%$ & $28(22 \%)$ & $9(22 \%)$ & \\
\hline Living with adult & $95(75 \%)$ & $28(70 \%)$ & 0.54 \\
\hline Born outside Sweden & $18(14 \%)$ & $9(23 \%)$ & 0.23 \\
\hline \multicolumn{4}{|l|}{ Medications } \\
\hline Analgetics & 87 (69\%) & $31(78 \%)$ & 0.42 \\
\hline Neuroleptica & $59(47 \%)$ & $15(38 \%)$ & 0.36 \\
\hline
\end{tabular}

WP Widespread pain, FIQ Fibromyalgia Impact Questionnaire Education in Not followed-up: $n=39$. In bold: $p$-values $<0.05$

This result is in line with a previous follow-up study in which an improvement of $11 \mathrm{~mm}$ was found over 3 years in patients with FM [8]. On the contrary the present results are contradictory to the findings of an 11 year follow-up in FM by Wolfe et al. which did not show a clinically relevant improvement in pain, fatigue or overall health status [10]. The divergent results could be due to different study settings; primary care in the present study versus secondary or tertiary care in the Wolfe study.
An individual change in pain intensity of 30 to $50 \%$ from baseline has been suggested to reflect a moderate clinically important improvement for patients with chronic pain [14, 15], which in the present study was found for $9 \%$ of the women. A substantial improvement in pain intensity is considered to be reflected by an individual change of at least $50 \%[14,15]$ which was achieved by $16 \%$ of the women in the present study. These results are in line with a previous 5 year follow-up 
Table 2 Distributions of pain and other health related variables at baseline, 10 to 12 year follow-up and change from baseline to follow-up. Number and percent of participants that improved are presented for each variable $(n=121-126)$

\begin{tabular}{|c|c|c|c|c|c|}
\hline & $\begin{array}{l}\text { Baseline } \\
\text { Mean (SD) } \\
\text { Median (Min;Max) }\end{array}$ & $\begin{array}{l}\text { Follow-up } \\
\text { Mean (SD) } \\
\text { Median (Min;Max) }\end{array}$ & $\begin{array}{l}\text { Change } \\
\text { Mean (SD)Median } \\
(\text { Min; Max) } \\
\left(95 \% \text { Cl for Mean) }{ }^{a}\right.\end{array}$ & Improved $n(\%)$ & $p$-value for change \\
\hline FIQ Pain $(0-100) n=123$ & $\begin{array}{c}68.3(18.7) \\
70.0(20 ; 100)\end{array}$ & $\begin{array}{c}59.4(22.0) \\
63.0(6 ; 100)\end{array}$ & $\begin{array}{c}-9.2(23.3) \\
-5.0(-72 ; 45) \\
(-13.3 ;-5.0)\end{array}$ & $75(61)$ & $<.0001$ \\
\hline Pain distribution (0-18) $n=126$ & $\begin{array}{c}13.2(3.4) \\
13.0(4 ; 18)\end{array}$ & $\begin{array}{c}11.1(4.7) \\
11.5(2 ; 18)\end{array}$ & $\begin{array}{c}-2.0(4.2) \\
-2.0(-15 ; 7) \\
(-2.7 ;-1.2)\end{array}$ & $74(59)$ & $<.0001$ \\
\hline FIQ total $(0-100) n=125$ & $\begin{array}{c}63.5(16) \\
64.6(14 ; 96)\end{array}$ & $\begin{array}{c}50.4(20) \\
51.6(10 ; 96)\end{array}$ & $\begin{array}{c}-13.3(17.9) \\
-10.0(-58 ; 38) \\
(-16.4 ;-10.2)\end{array}$ & $93(75)$ & $<.0001$ \\
\hline FIQ fatigue $(0-100) n=124$ & $\begin{array}{c}78.5(20.3) \\
83.0(15 ; 100)\end{array}$ & $\begin{array}{c}71.7(24.7) \\
79.0(0 ; 100)\end{array}$ & $\begin{array}{c}-7.0(21.5) \\
-3.0(-80 ; 43) \\
(-10.8 ;-3.3)\end{array}$ & $67(54)$ & 0.001 \\
\hline HADS-D $(0-21) n=124$ & $\begin{array}{c}6.8(3.9) \\
6.0(0 ; 16)\end{array}$ & $\begin{array}{c}5.8(4.2) \\
5.0(0 ; 17)\end{array}$ & $\begin{array}{c}-0.9(3.9) \\
-1.0(-13 ; 8) \\
(-1.6 ;-0.2)\end{array}$ & $64(52)$ & 0.020 \\
\hline HADS-A $(0-21) n=124$ & $\begin{array}{c}8.2(5.2) \\
7.0(0 ; 20)\end{array}$ & $\begin{array}{c}7.7(4.7) \\
7.0(0 ; 18)\end{array}$ & $\begin{array}{c}-0.5(4.4) \\
-1.0(-12 ; 10) \\
(-1.3 ; 0.3)\end{array}$ & $65(52)$ & 0.32 \\
\hline SF36 PCS $(0-100) n=121$ & $\begin{array}{l}29.7(8.2) \\
29.3(11 ; 50)\end{array}$ & $\begin{array}{c}33.9(10.2) \\
33.4(10 ; 58)\end{array}$ & $\begin{array}{c}4.0(10.2) \\
4.0(-15 ; 34) \\
(2.2 ; 5.8)\end{array}$ & $76(63)$ & $<0.001$ \\
\hline SF36 MCS $(0-100) n=123$ & $\begin{array}{l}39.5(13.4) \\
41.2(11 ; 67)\end{array}$ & $\begin{array}{l}39.6(14.7) \\
43.0(0 ; 68)\end{array}$ & $\begin{array}{c}0.2(14.5) \\
1.4(-67 ; 30) \\
(-2.4 ; 2.7)\end{array}$ & $81(66)$ & 0.42 \\
\hline SCI-93 (0-140) $n=122$ & $\begin{array}{l}76.3(24.0) \\
76.3(26 ; 132)\end{array}$ & $\begin{array}{c}69.4(26.2) \\
66.0(6 ; 128)\end{array}$ & $\begin{array}{c}-6.5(20.8) \\
-3.5(-82 ; 33) \\
(-10.3 ;-2.8)\end{array}$ & $68(56)$ & 0.005 \\
\hline LTPAI (h) $n=122$ & $\begin{array}{l}5.0(3.9) \\
4.0(0 ; 23)\end{array}$ & $\begin{array}{c}5.5(5.4) \\
4.0(0 ; 34)\end{array}$ & $\begin{array}{c}0.5(5.6) \\
0.0(-11 ; 27) \\
(-0.5 ; 1.5)\end{array}$ & $51(42)$ & 0.67 \\
\hline
\end{tabular}

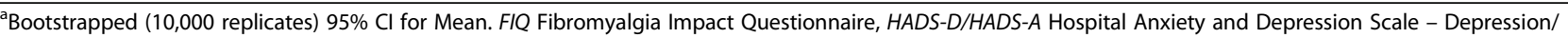
Anxiety, SF-36 Short-form 36, PCS Physical Component Summary, MCS Mental Component Summary, SCI-93 Stress and Crisis Inventory, LTPAI Leisure Time Physical Activity Instrument In bold: $p$-values $<0.05$.

study in FM, which found a moderate improvement in pain intensity for $10 \%$ and a substantial improvement for $12 \%$ of the population over time [15]. However, another follow-up study found that $36 \%$ of patients with FM reported at least 30\% improvement in pain intensity after 3 years [8]. The suggested cut-offs for level of improvement in pain intensity were based on clinical trials [14]. In the present study the limits were used as a guidance of how to interpret the clinical relevance of the

Table 3 Level of impairment based on FIQ total score for the $126^{a}$ women participating in the 10 to 12 year follow-up

\begin{tabular}{lcc}
\hline & Baseline $n(\%)$ & Follow-up $n(\%)$ \\
\hline Mild impairment $(<39 \mathrm{p})$ & $11(9)$ & $43(34)$ \\
Moderate impairment $(\geq 39$ to $<59$ p) & $35(28)$ & $40(32$ \\
Severe impairment $(\geq 59 \mathrm{p})$ & $79(63)$ & $42(33)$ \\
\hline
\end{tabular}

${ }^{a} 1$ missing value was found both at baseline and at follow-up for FIO total score change in pain intensity in a cohort over time, why the conclusion should be interpreted with caution.

The distribution of pain was found to be improved over 10 to 12 years in the present study population with a mean reduction of two pain sites. This improvement in pain spread corresponds to previous findings in general populations which have shown that some persons can recover from CWP over time [8, 9].

Lower levels of stress symptoms at baseline assessed with the SCI-93 and higher pain intensity predicted higher chance of substantial improvement in pain intensity after 10 to 12 years in the present study. The SCI-93 reflects the severity of clinical manifestations of stress related to the autonomous nervous system. Physiological stress mechanisms have also been suggested to play a role in the maintenance of widespread pain in FM [30, 31], which supports the findings in the present study. A high degree of clinical stress symptoms in women with FM and CWP might be related to the amount of 
Table 4 Univariable logistic regression analyses of predictors of a reduction in FIQ pain $\geq 50 \%$ after 12 years. Odds ratios with $95 \%$ confidence intervals and p-values, adjusted for FIQ pain at baseline $\left(n=123^{\mathrm{a}}\right)$

\begin{tabular}{lcc}
\hline Baseline values & \multicolumn{2}{l}{ Dependent variable $\geq 50 \%$ reduction in FIQ pain } \\
\cline { 2 - 3 } & OR (95\% Cl) & $p$-value \\
\hline Age, per 10 years & $1.00(0.95-1.06)$ & 0.85 \\
Education, 1-4 & $0.97(0.47-2.03)$ & 0.95 \\
Body Mass Index & $0.95(0.86-1.05)$ & 0.32 \\
FIQ total, per ten units & $0.66(0.45-0.96)$ & $\mathbf{0 . 0 3 1}$ \\
FIQ pain, per ten mm & $1.19(0.91-1.57)$ & 0.21 \\
HADS anxiety, 0-14 & $0.93(0.84-1.03)$ & 0.14 \\
HADS depression, 0-14 & $0.85(0.74-0.99)$ & $\mathbf{0 . 0 3 0}$ \\
SF-36 PCS, per ten units & $0.70(0.35-1.41)$ & 0.31 \\
SF-36 MCS, per ten units & $1.87(1.18-2.97)$ & $\mathbf{0 . 0 0 8}$ \\
SCI-93, per ten units & $0.79(0.64-0.98)$ & $\mathbf{0 . 0 3 2}$ \\
LTPAl, hours & $0.97(0.85-1.11)$ & 0.67 \\
6 min walk test, meter & $1.00(0.99-1-01)$ & 0.97 \\
Randomization in previous RCT & $1.50(0.57-3.99)$ & 0.42 \\
\hline
\end{tabular}

$p$-values less than 0.05 in bold

FIQ Fibromyalgia Impact Questionnaire, HADS Hospital Anxiety and Depression Scale, SF-36 Short-form 36, PCS Physical Component Summary, MCS Mental Component Summary, SCI-93 Stress and Crisis Inventory, LTPAI Leisure Time Physical Activity Instrument

${ }^{a}$ Data for 123 women were included in the analyses of improvement in pain intensity (FIQ pain), due to missing values. For HADS anxiety, HADS depression, SF-36 PCS, SF-36 MCS and SCI-93 the number of cases included in analyses were 120-122

neurobiological aberrations which have been observed in patients with chronic pain in the hypothalamic-pituitaryadrenal (HPA) axis and the noradrenaline-sympathetic system, components of the human stress response [30, 31]. Exposure to stress over a long period of time may trigger dysfunctional biological and psychological stress mechanisms which could have a negative impact on the patient's health and possibilities to recovery [32]. The results of the present study underlines the importance of development of treatments and strategies in health care to reduce stress in women with FM and CWP.

In the univariable analyses, pain intensity at baseline was not significantly associated with $\geq 50 \%$ improvement in pain intensity after 10 to 12 years. However, in the multivariable analysis, lower stress levels and higher pain intensity at baseline were found to predict substantial improvement in pain intensity. The fact that patients with higher levels of pain are more likely to improve in pain over time could partly be due to regression to the mean. The findings in the present study enhances the assumption that stress level is an important aspect to take into consideration in women with FM and CWP, especially for patients with more severe pain. The AUCvalue for the model was 0.730 , indicating acceptable goodness of the model, and that other factors not found in the present study may play a role in substantial improvement in pain intensity over time.

Besides clinical symptoms of stress, the univariable models in the present study showed that mental aspects of health such as symptoms of depression and the SF-36
MCS may play an important role in predicting chances of substantial pain reduction after 10 to 12 years. Physical aspects of health such as SF-36 PCS, level of physical activity and walking capacity at baseline were not found to be associated with substantial improvement in pain intensity after 10 to 12 years. However, although physical function did not predict improvement in pain over time in the present study, physical exercise has been found to contribute to improvements in all core symptoms of FM and CWP in intervention studies [33-36]. It is thus crucial to promote physical activity and physical function in treatments for patients with FM and CWP in order to improve general health and reduce the risk for concomitant disorders related to a sedentary life-style.

For FIQ total score the mean improvement from baseline to follow-up corresponds to a change of $20 \%$ which is higher than the minimal clinically important change for the FIQ total score in women with FM which has been suggested to be around 14\% [21] . Although this interpretation is based on intervention studies and a shorter time period [21] it could be used as a guidance for interpretation of the clinical relevance of change in overall health in the present study.

The number of patients with severe impairment [21] has halved in the present study at the 10 to 12 year follow-up. Still, over $30 \%$ of the women experienced severe impairment after 10 to 12 years which underlines the importance of finding adequate methods to support these patients over time. 
Small but statistically significant improvements over time was also found in the present study for other important aspects of health such as fatigue, depression, symptoms of stress and physical component of health related quality of life. These findings are in line with the results of a previous five-year follow-up reporting small improvements in fatigue, depression and overall health [12]. However, another follow-up study showed no improvement in fatigue and depression in women with FM over time [11]. Discrepancies in results between the studies might be due to the use of different questionnaires or differences in population characteristics.

Although the patients in the present study improved over time in many aspects of health, their mean levels of pain, fatigue and health related quality of life still reflect severe impairment. Symptoms of anxiety and mental aspects of health related quality of life did not change significantly over time.

The total amount of time spent on physical activity in leisure time did not change significantly over 10 to 12 years in the present study, the mean value being around 5 $\mathrm{h} /$ week at both examinations, including activities on low and moderate intensity. This result reflects the difficulties of being physically active for patients with chronic pain.

The follow-up rate in the present study was high, $76 \%$, and the patients who were followed up did not differ significantly in baseline values from the ones who did not participate in the follow-up, except for a slightly higher number of tender points.

\section{Limitations}

The present follow-up study aimed to assess the course of symptoms over time in women with FM or CWP. The population participated 10 to 12 years earlier in an RCT comprising an intervention of pool exercise and patient education [17]. Therefore, the cohort might consist of participants with a positive attitude towards physical exercise, which has to be taken into consideration when interpreting the generalizability of the results. The impact of the exercise program is considered to be negligible after 10 to 12 years and previous randomization were not found to be associated with improvement in pain intensity in the univariable analyses of predictors. The participants were recruited from primary health care centers in which many patients with chronic pain are offered participation in patient education, why the population in the present study is considered to reflect average patients with FM and CWP found in Swedish primary health care.

Symptoms in FM and CWP fluctuate from day to day and another limitation of the present study is that the 10 to 12 year follow-up was performed at only one occasion. A part of the small but significant improvement found in pain intensity and other symptoms could possibly be due to a natural regression to the mean over time. Also, other variables than baseline symptoms and characteristics might have influenced the course of symptoms over time, such as concomitant disorders, different treatments or major life changes in work and social relations. No information of pharmacological or non-pharmacological treatments or other life changes during the study period were gathered since it was not likely that the participants could recall accurate information after 10 to 12 years.

\section{Conclusions}

A majority of women with FM and CWP appear to have a positive course of pain and other symptoms on group-level over 10 to 12 years, which should be communicated to these patients in health care. In the present study, the women were found to improve in pain intensity with $13 \%$ over 10 to 12 years. A substantial improvement in pain intensity was achieved by $16 \%$ of the women. Also the pain spread, overall health, fatigue, symptoms of depression, stress and physical component of health related quality of life were found to improve over time, however the mean improvements were small.

Lower levels of clinical stress symptoms and higher pain intensity predicted higher chances of substantial improvement in pain intensity 10 to 12 years later. Therefore, stress is recommended to be assessed and taken in to account in the planning of treatments of patients with FM and CWP.

\section{Abbreviations \\ 6MWT: 6 min walk test; AUC: Area under the receiving operating curve; BMI: Body Mass Index; CWP: Chronic Widespread Pain; FIQ: Fibromyalgia Impact Questionnaire; FM: Fibromyalgia; HADS: Hospital Anxiety And depression Scale; SCI-93: Stress and Crisis Inventory; LTPAl: Leisure Time Physical Activity Instrument; MCS: Mental Component Summary; OR: Odds Ratio; PCS: Physical Component Summary; RCT: Randomised Controlled Trial; SF-36: Short-Form 36; VAS: Visual Analogue Scale}

\section{Acknowledgements}

Acknowledgements to the Närhälsan Uddevalla Rehabilitation Centre, the Närhälsan Sörhaga Rehabilitation Centre and the Department of Physiotherapy, Sahlgrenska University Hospital, Gothenburg, Sweden for providing premises for data collection. The statistical adviser was Nils-Gunnar Pehrsson.

\section{Authors' contributions}

$A B$ and $K M$ planned the design of the study. $A B, S J, L N$ and $M J$ collected the data. All authors participated in writing the manuscript and all authors read and approved the final manuscript.

\section{Funding}

The Healthcare Committee, Region Västra Götaland, Sweden (application no VGFOUREG-551351 and VGFOUREG-586471) funded time for data collection and analysis, interpretation of data and manuscript writing.

Availability of data and materials

The datasets used and/or analyses during the current study are available from the corresponding author on reasonable request.

Ethics approval and consent to participate

The study was approved by The Regional ethical review board in Gothenburg, University of Gothenburg, no 097-16. Written and oral information was given to all participants and written consent was obtained from all participants.

Consent for publication

Not applicable. 


\section{Competing interests}

The authors declare that they have no competing interests.

\section{Author details}

${ }^{1}$ Institute of Neuroscience and Physiology, Department of Health and Rehabilitation, Physiotherapy Unit, Sahlgrenska Academy, University of Gothenburg, Gothenburg, Sweden. ${ }^{2}$ Research and Development Primary Health Care, Region Västra Götaland, Sweden. ${ }^{3}$ Närhälsan Rehabilitation Centres, Region Västra Götaland, Sweden.

\section{Received: 8 August 2018 Accepted: 31 May 2019}

Published online: 24 June 2019

\section{References}

1. Mansfield KE, Sim J, Jordan JL, Jordan KP. A systematic review and metaanalysis of the prevalence of chronic widespread pain in the general population. Pain. 2016;157(1):55-64.

2. Gran JT. The epidemiology of chronic generalized musculoskeletal pain. Best Pract Res Clin Rheumatol. 2003;17(4):547-61.

3. Wolfe F, Smythe HA, Yunus MB, Bennett RM, Bombardier C, Goldenberg DL, et al. The American College of Rheumatology 1990 criteria for the classification of fibromyalgia. Report of the multicenter criteria committee. Arthritis Rheum. 1990;33(2):160-72.

4. Wolfe F, Ross K, Anderson J, Russell IJ, Hebert L. The prevalence and characteristics of fibromyalgia in the general population. Arthritis Rheum. 1995:38(1):19-28.

5. Mease P, Arnold LM, Choy EH, Clauw DJ, Crofford L, Glass JM, et al. Fibromyalgia syndrome module at OMERACT 9: domain construct. J Rheumatol. 2009;36(10):2318-29.

6. Rohrbeck J, Jordan K, Croft P. The frequency and characteristics of chronic widespread pain in general practice: a case-control study. Br J Gen Pract. 2007;57(535):109-15.

7. Maquet D, Croisier JL, Renard C, Crielaard JM. Muscle performance in patients with fibromyalgia. Joint Bone Spine. 2002;69(3):293-9.

8. Poyhia R, Da Costa D, Fitzcharles MA. Pain and pain relief in fibromyalgia patients followed for three years. Arthritis Rheum. 2001;45(4):355-61.

9. Mundal I, Grawe RW, Bjorngaard JH, Linaker OM, Fors EA. Prevalence and long-term predictors of persistent chronic widespread pain in the general population in an 11-year prospective study: the HUNT study. BMC Musculoskelet Disord. 2014;15:213.

10. Wolfe F, Walitt BT, Katz RS, Lee YC, Michaud KD, Hauser W. Longitudinal patterns of analgesic and central acting drug use and associated effectiveness in fibromyalgia. Eur J Pain. 2013;17(4):581-6.

11. Baumgartner E, Finckh A, Cedraschi C, Vischer TL. A six year prospective study of a cohort of patients with fibromyalgia. Ann Rheum Dis. 2002;61(7):644-5.

12. Reisine S, Fifield J, Walsh S, Forrest DD. Employment and health status changes among women with fibromyalgia: a five-year study. Arthritis Rheum. 2008:59(12):1735-41.

13. Salaffi F, Stancati A, Silvestri CA, Ciapetti A, Grassi W. Minimal clinically important changes in chronic musculoskeletal pain intensity measured on a numerical rating scale. Eur J Pain. 2004;8(4):283-91.

14. Dworkin RH, Turk DC, Wyrwich KW, Beaton D, Cleeland CS, Farrar JT, et al. Interpreting the clinical importance of treatment outcomes in chronic pain clinical trials: IMMPACT recommendations. J Pain. 2008;9(2):105-21.

15. Walitt B, Fitzcharles MA, Hassett AL, Katz RS, Hauser W, Wolfe F. The longitudinal outcome of fibromyalgia: a study of 1555 patients. J Rheumatol. 2011;38(10):2238-46.

16. Bergman S, Jacobsson LT, Herrstrom P, Petersson IF. Health status as measured by SF-36 reflects changes and predicts outcome in chronic musculoskeletal pain: a 3-year follow up study in the general population. Pain. 2004;108(1-2):115-23.

17. Mannerkorpi K, Nordeman L, Ericsson A, Arndorw M. Pool exercise for patients with fibromyalgia or chronic widespread pain: a randomized controlled trial and subgroup analyses. J Rehabil Med. 2009;41(9):751-60

18. Bergman S. Psychosocial aspects of chronic widespread pain and fibromyalgia. Disabil Rehabil. 2005;27(12):675-83.

19. Burckhardt CS, Clark SR, Bennett RM. The fibromyalgia impact questionnaire: development and validation. J Rheumatol. 1991;18(5):728-33.

20. Hedin PJ, Hamne M, Burckhardt CS, Engstrom-Laurent A. The fibromyalgia impact questionnaire, a Swedish translation of a new tool for evaluation of the fibromyalgia patient. Scand J Rheumatol. 1995;24(2):69-75.
21. Bennett RM, Bushmakin AG, Cappelleri JC, Zlateva G, Sadosky AB. Minimal clinically important difference in the fibromyalgia impact questionnaire. J Rheumatol. 2009;36(6):1304-11.

22. Zigmond AS, Snaith RP. The hospital anxiety and depression scale. Acta Psychiatr Scand. 1983;67(6):361-70.

23. Herrmann C. International experiences with the hospital anxiety and depression scale--a review of validation data and clinical results. J Psychosom Res. 1997;42(1):17-41.

24. Krafft B, Nystrom C. High level of stress and immature defense make for a vicious circle in chronic pain. Patients with pain syndromes caught in unresolved crisis as a study shows. Lakartidningen. 2002;99(41):4040-3.

25. Ware JE Jr, Sherbourne CD. The MOS 36-item short-form health survey (SF-36). . Conceptual framework and item selection. Med Care. 1992;30(6):473-83.

26. Mannerkorpi K, Hernelid C. Leisure time physical activity instrument and physical activity at home and work instrument. Development, face validity, construct validity and test-retest reliability for subjects with fibromyalgia. Disabil Rehabil. 2005;27(12):695-701.

27. Mannerkorpi K, Svantesson U, Carlsson J, Ekdahl C. Tests of functional limitations in fibromyalgia syndrome: a reliability study. Arthritis Care Res. 1999;12(3):193-9.

28. Altman D. Practical statistics for medical research. London: Chapman \& Hall/ CRC; 1999.

29. Hanley JA, MCNeil BJ. The meaning and use of the area under a receiver operating characteristic (ROC) curve. Radiology. 1982;143(1):29-36.

30. Kadetoff D, Kosek E. Evidence of reduced sympatho-adrenal and hypothalamic-pituitary activity during static muscular work in patients with fibromyalgia. J Rehabil Med. 2010;42(8):765-72.

31. Price DD, Staud R. Neurobiology of fibromyalgia syndrome. J Rheumatol Suppl. 2005;75:22-8.

32. Clauw DJ, Williams DA. Relationship between stress and pain in workrelated upper extremity disorders: the hidden role of chronic multisymptom illnesses. Am J Ind Med. 2002;41(5):370-82.

33. Ericsson A, Palstam A, Larsson A, Lofgren M, Bileviciute-Ljungar I, Bjersing J, et al. Resistance exercise improves physical fatigue in women with fibromyalgia: a randomized controlled trial. Arthritis Res Ther. 2016;18:176.

34. Larsson A, Palstam A, Lofgren M, Ernberg M, Bjersing J, Bileviciute-Ljungar I, et al. Resistance exercise improves muscle strength, health status and pain intensity in fibromyalgia-a randomized controlled trial. Arthritis Res Ther. 2015;17:161.

35. Bidonde J, Busch AJ, Webber SC, Schachter CL, Danyliw A, Overend TJ, et al. Aquatic exercise training for fibromyalgia. Cochrane Database Syst Rev. 2014;10:CD011336.

36. Bidonde J, Busch AJ, Bath B, Milosavljevic S. Exercise for adults with fibromyalgia: an umbrella systematic review with synthesis of best evidence. Curr Rheumatol Rev. 2014;10(1):45-79.

\section{Publisher's Note}

Springer Nature remains neutral with regard to jurisdictional claims in published maps and institutional affiliations.

Ready to submit your research? Choose BMC and benefit from:

- fast, convenient online submission

- thorough peer review by experienced researchers in your field

- rapid publication on acceptance

- support for research data, including large and complex data types

- gold Open Access which fosters wider collaboration and increased citations

- maximum visibility for your research: over $100 \mathrm{M}$ website views per year

At $\mathrm{BMC}$, research is always in progress.

Learn more biomedcentral.com/submissions 